\title{
Discussing the Inheritance and Evolution of the Patronus Mahakala
}

\section{-- Taking the Mahakala of Guangren Temple as an Example}

\author{
Le Zhang
}

School of Art, Northwest University, Shannxi 710127, China

\begin{abstract}
As the only Gelugpa temple in Northwest China and the only Green Tara Dojo in China, Guangren Temple, a Tibetan Buddhism temple in Xi'an, Shaanxi Province, is crucial to the study of Tibetan Buddhism development in the mainland. This paper takes the Patronus Mahakala as the starting point, because it is not only one of the most important Patronus, but also the incarnation of Shiva, one of the most critical gods in Hinduism. The extraction elements from the statues and the establishment of a connection with Tibetan Buddhism will help explore the origin of the external components of the sculptures in Buddhism and Tibetan Buddhism. Furthermore, through clarifying the process of religious transmission and development, the conflict and integration of the intersectarian, find the impact and evolution of the shape of Gods.
\end{abstract}

Keywords: Mahakala; Guangren Temple; Tibetan Buddhism; India.

\section{Introduction}

In the Tibetan Buddhist temples in China, Mahakala usually appears as a Patronus. There are many viewpoints about the origin and the image of the Mahakala in Chinese academy circles. Among them, few claims that it originated from Vishnu; others find that the prototype of the Mahakala has the exact spiritual origin as the Brahmin and Hindu deities, such as Brahmanism Rudra, the Hindu Goddess Kali, and the Buddhist Mahesvara. All these "archetypes" points to the same Hindu God, Shiva. The image of Mahakala appeared in Brahmanism first, but the Hindu temple, which originated from Brahmanism, has few relics in China, apart from Quanzhou. Fortunately, Tibetan Buddhism in China has some basis of belief; the image of Mahakala was widely seen in the temple of Protection. It leaves a primary condition to the research on the appearance of Mahakala in China.

Located in the northwest corner of the city wall of the Ming Dynasty, Guangren Temple, the Tibetan Buddhism temple in Xi'an, Shaanxi Province, was founded in 1705 of Qing Dynasty (44-ad Kangxi). It is the only Geru Temple in the inland area of northwest China, where Tibetan Buddhism did not flourish, and is the only Green Tara main Dojo in China, so its status is very precious. This paper takes the Mahakala Statue of Guangren Temple as a starting point, extracts its structure characteristic and symbolic element, makes the comparative study with the structure of Hindu Deities, and tries to deduce their homology and the rheology. Again, this proves that the religious culture has always been a factor that cannot be ignored in spread of spiritual culture. Influence and inheritance, as well as cross-regional studies of civilization were existed around the area of the Silk Road.

\section{Mahakala as Patronus: The Origin and Establishment of the Image of the Mahakala}

There is not a definite conclusion about the time when the image of Mahakala was established and introduced to China. Still it is generally confirmed that the image originated from Brahmanism in India and has a direct connection with the Hindu god Shiva. The study of the establishment and development of the image of Shiva, especially from the perspective of the body and symbolic elements, reconfirms the claim by the archaeologist and anthropologist Dr. V. S. Wakankar said that the image, which was found in the Rock Shelters of Bhimbetka, Vindhya Range, was the earliest images of Shiva. This traces the beginnings of Shiva back to B.C. 3000 to B.C. 1900. Through further research, the image of Shiva was developed and established through "The stage of procreation 
worship," "The stage of nature a worship" and "The stage of combination of Aryan civilization and Dravidian civilization." [1]

In the book of reflections of Indian Culture, the author talks about the "religious spirit" in India, saying: "The common value of religious spirit is the premise of the existence of universal religion. From this perspective, the Indians were the teacher of all the religious scholars. They have the most powerful saying in the construction of a multi-religious symbiosis", and add to "though there are many names and incarnations of the Indian gods, they are indeed one God" [2] This is an interpretation of the development of religion in India, and help us understand the diversity and inclusiveness better. Then, how about Buddhism in China? Is it from India to China? About this, Mr. Wang Yao said that one of the obstacles to developing Buddhism in Tibet areas was the local Bon Religion. The master Padmasambhava was invited and he proposed the assimilation of the Deities which worshiped by the Tibetan into the patron saint of Buddhism. Both sides were happy, and the Pantheon of Buddhism was expanded. [3] The "compromise strategy" of Buddhism to the native Bon religion contributed to the development of Tibetan Buddhism. Thus, it is easier to understand why the Shiva, one of the three great gods of Hinduism (also known as neo-Brahmanism), has been debasement as the status of the patron saint in Tibetan Buddhism.

The earliest day that Buddhism spread to China was the year of 137 B.C., and a temple was founded in the foothills of Elan Mountain, [4] but the temple is long gone, so there is no other reliable evidence. Tibetan Buddhism can be traced back to the earliest days of the ancient Kingdom of Zhangzhung, when the Bon religion rose. Tibetan Buddhism is the result of the assimilation and transformation of Buddhism from India and local religions in Tibet, so it is reasonable to trace its origin to the emergence of the Bon religion. Then as the patron saint of the Tibetan Buddhism, which is also the product of the collision and the integration of the two faith, what is the exact time to make the image of Mahakala? For this, Li Ling points out that "the mystery of the Mahakala" means the Guardian God. She pointed it out in one of her articles on the textual research of the image of the Mahakala, and the wrath of the Mahakala appeared after esotericism. The esoteric tendency of Buddhism began after $7^{\text {th }}$ century A.D. Although there have some proves that the Mahakala was offered before the $7^{\text {th }}$ century, the duty of God was to protect the food and money, and did not see the wrath image. Thus, being as the Patronus in Tibetan Buddhism, the development and perfection of the image and the ritual track of the Mahakala, coincided with the Esoteric teaching of Buddhism, which took place around the $7^{\text {th }}$ and $8^{\text {th }}$ centuries.

\section{The Features and Spreading of the Mahakala}

Although in the hall of the Patronus of Guangren Temple, Yamantaka is placed in the center of the five Dharma protections, in numerous documents, researchers tend to think that "the Mahakala is the head of the Dharma protection in Tibetan Buddhism." [5] Mahakala (Daheitian) written as "Mahākāla" in Sanskrit, and the front part "Mahā" means "big(大)," "kāla" has the meaning of "black(黑)" and “time(时),” therefore, “Dahei（大黑）” and “Dashi（大时）” can be used as its name in Chinese. In Tibetan, Mahakala is called "Gongbu" or "gongbao," which means all things are safe and healthy. In the Chinese literature, "Mahakala is also known as Daheishen (大黑神) or Dahetianshen（大黑天 神), which is the translation of the Mohegaro, Mohegero, Mohegechi, Mahagechi, Moyigechi, Mahagela, Mahagechi, etc. Its origin is a Hindu Brahmanism deity, but became the esoteric deity around the $7^{\text {th }}$ century." [6]

\subsection{The Classification and the Characteristics of the Mahakala Statue}

From Brahmanism to the evolution of Hinduism, Buddhism, and other religious faction, and finally to Tibetan Buddhism, and the priesthood and the image of the Mahakala have changed a lot. In addition, the belief of the Mahakala is widespread among the Han, Tibetan, Mongols, Manchu, Yi people, Bai people, and other multi-ethnic groups in China, with the scattered regions and complexity of historical and cultural background of those various ethnic groups, caused the summary of this God- 
image system is significantly complicate. As early as the $15^{\text {th }}$ year of Jiajing in the Qing Dynasty, the book of collecting complete images of God, "The collection of the God hais' acheaivement by Baosheng: Baoshengyiming" was published in 1810. In the 1980s, the book named "Deities of Tibetan Buddhism", which is based on the "The image of the painting according to the Baosheng, Natangbaifa and Jingangman," was published by the Shaanxi Normal University Press in 2010. "Deities of Tibetan Buddhism" collected 510 deities, who were painted as colored miniature Thangka, also introduced their names, holding substance and body posture. In his doctoral dissertation, Huang Jiehua summed up 52 of the names of the Mahakala according to the "The image of the painting according to the Baosheng, Natangbaifa and Jingangman,"[7] and classified them. This is not only a comprehensive discussion of the name and style of the Mahakala, but also an important reference for this study. The book named "Oracles \& Demons of Tibet-The Cult and Iconography of the Tibetan Protective Deities" was published in 2000. The author of the book Rene de Nebelski Vojkwoitz referred that based on the literature of Tibetan iconography, there are "seventy two or seventy five forms of the Mahakala".[8] In addition, there are different opinions about the number and forms of the statue of the Mahakala, here will not point it one by one. However, during the process of documentation, interpretation and induction of the relevant literature and the complicated branches of sects, there appeared various non-convergences occurred. So, it is difficult to define the specific number of the pattern of the Mahakala, at least, there is no consensus on the exact number. However, the common pattern existed in the Mahakala, and it makes relatively easy to interpret and classify the image.

Regardless of how many changes happen to the Mahakala, which were transferred from India to the Tibetan Buddhism in China, a researcher found that after the Yuan Dynasty, in the system of Tibetan Buddhism in China, there are four common form fo the Mahakala statues in China. There are "the Sakay is a two-arm Mahakala, also known as the punishment god of Mahakala, four-am Mahakala, which is known as the embodiment of the Cakrasamvara, six-arm Mahakala and it has black and white, white six-arm Mahakala, and is charge of the wealth." [5] This classification is mainly based on the shape of body and color, and the shape of body is mainly based on the number of arms. Those methods are very similar to the classification among the people. While recalling the 52 thanka on the Mahakala in the book of "Deities of Tibetan Buddhism", we can conclude that the classification based on the forms of arms and color is very one-sided, but if we classify it according to the sects and priesthood, it will be complicated and difficult to form a system. Therefore, the form of the Mahakala is still classified by the shape of arm, such as two-arm image, four-arm image, sixarm image and so on.

Although the style of the Mahakala changes a lot, it has the same origin, so its body shape, appearance, holding materials, and clothing have some common factor. Take the six-arm Mahakala as an example-this is not only the form of the Mahakala in the temple of the protectors in Guangren Temple, but also is the most common one- have number of arms, and the holding object and clothing is also relatively complex. The six-armed Mahakala is also considered as the most perfect form, usually wrathful, raised in anger, and adorned with a crest of five skulls. The face features a third eye on the forehead and prominent fangs. The neck and wrists are often decorated with snakes. The body is mostly black or blue, with tiger skin around the waist. From the neck to the waist, it is often decorated with a human head or skull. The foot stepped on the devil with the human head and body. In many Thankas, the elephant hide, which is joined from the bottom, is also pulled apart by the top pair of the six arms. The Mahakala usually holdings Yue Dao, drum, rosary, Trident, human skull (objects), Long Rod, rope (small intestine), Aquarius, elephant skin and so on. As mentioned above, there are up to seventy-five styles of the Mahakala. Still the most common and typical elements of the six-armed Mahakala was be extracted, and their specific definition is discussed later.

\subsection{The Spread and Distribution of the Mahakala Statue}

The Mahakala is one of the incarnations of Shiva in India. Some scholars have translated this incarnation as "Dashi", also means the god of death. In this image, Shiva "cancels time, makes all 
transmigration permanent and all things exist in eternity." [9] As the god of death, Shiva has five heads and stand on the body of a lion. I did not see this statue during my visit to India. Out of India, Nepal has the largest concentration of the Mahakala, because more than 80 percent of its population is believe in Hindu. At there the Mahakala appeared in front of the temple, small shrines of an ordinary people's family or in large volumes appear in important location of Durbar Square as a guardian to protect peace. Most of the Malakala in Nepal have six-arm and the head is large and the body is stocky, known as the KalaBhairava. "KalaBhairava" literally means two things, "black"and "horrible". "Bhairava" is one of Shiva's change images of "terror". Shiva appeared in terror means "Brahma killer", cutting off one of the Brahma's five head and also the "patricide", cutting of his father-in-law's head. Those descriptions are very terrible, showing the power of Shiva in the "destruction" function. In India, Shiva's image of terror are considered as protectors of travelers, vagabonds or ascetic, and are usually housed in a shrine attached to the temple that serves as the temple's guardian. Although the pattern of the Mahakala statue in Nepal is not the same as that India, the gods played and functioned as the same in India. Comparatively, because of China's large territory and many ethnics, the image of the Mahakala encountered conflicts and mingle with ethnicity and local culture in China, and it caused the situation more complicated.

Buddhism was introduced to China from India through Central Asia across Pamir Mountains in the first century A.D. [4] It began to spread to Tibet on a large scale during the time of the establishment of Tibetan Dynasty by Songtsan Gampo. About 100 years after Langdarma destroyed Buddhism, the late spread of Tibetan Buddhism in the $10^{\text {th }}$ century led to the revival of Buddhism in Tibet and it developed a Tibetan Buddhist system with ethnic and regional characteristics. As the most important patronus of Tibetan Buddhism, in the area around the Tibet, there are many and represented statue of the Mahakala. For this, scholar Zhu Yuemei said, "the spreading of the Mahakala statue in China has distinct characteristics, and they are mainly distributed along the line of YunnanTibet-Dunhuang. Among which, the Tibet series was widely spread in Yuan and Qing dynasties, so most of the Mahakala statue distributed outside the line of Yunnan-Tibet-Dunhuang are belong to the Tibet series." [10] In a word, the distribution of the Mahakala in China is divided into a series from Yunnan and a series from Tibet. In fact, the Tibetan Buddhism and the Mahakala statue have developed not only in Tibetan areas and Yunnan, but also in the provinces of Sichuan, Qinghai and Gansu, which surround the Tibet region. If trace back the origin, did the comprehensive analysis of the patterns and the myth of the statue, it will show that no matter which route, all of the Mahakala statue were originated from the Shiva in Hinduism.

The distribution of the Mahakala as patronus in China is closely related to the Tibetan Buddhism, besides the Tibet region, in Yunnan area it was the most widely spread. Esoteric Buddhism began to spread in Yunnan around $8^{\text {th }}$ century A.D. and the Tibetan Buddhism was introduces by those monks who had taken refuge during the destruction of the Buddha by Langdarma. Added with the local believes, the Mahakala in Yunnan include many appeals, include fighting demons, protect the country, removing disease, living a long live, plenty of food and so on. However, when we recall one of the local legends of the Mahakala, the god who saved mankind by swelling the curse tally that was used as spread the plague, caused him turn black and become the god of black (Mahakala). This legend is identical to the Shiva, who swallowed the poison. In Shiva's case the poison only burned his neck, so get the name of "Neelkantha"(Sanskrit for green neck), which means blue throated in English. For this the Shiva has the "green neck phase" among his multi-phase. Therefore, I think the belief of Mahakala in Yunnan has direct connection with Hinduism, and is the origin and tributary relationship. In addition, in the research of "The evolution and cultural representation of the Mahakala belief among Hehuang and Taomin People", Niu Le pointed out that the local God "rhinoceros see" in Gansu and Qinghai regions is actually the same origin as the Mahakala in Yunnan. Many evidences show that the origin of the Mahakala statue in China, which distributed regional concentration and scattered at the same time, can be traced back to the Hindu gods. Therefore, a case study, such as Guangren Temple is helpful to the establishment of a complete genealogy of the Mahakala statue in China. 


\section{Extraction and Analysis of the Elements of the Mahakala Statue in Guangren Temple}

Located in the heart of Central area and cause of its strategic location, the capital city of Shaanxi Province, Xi'an was the capital of more than a dozen dynasties in Chinese history. During the reign of Zhengguan in Tang Dynasty, Princess Wencheng was married off from Chang'an (Xi'an) to Luoxie (Lhasa). She carried a large number of Buddhist statues, pagodas, sutras and so on, and it promoted the construction of Jokhang Temple. During the Kangxi period of Qing Dynasty, the Emperor Kangxi decided to establish the Guangren Temples in Xi'an, and important town of Northwest China. This is to win over the Mongols and strengthen the unity and stability of the multiethnic groups, because the Mongolian and Tibetan have the common belief of the Tibetan Buddhism.[11] From then on, the Guangren Temple used as a palace for Dalai Lama, the Panchen Lama and others on the pilgrimage to Beijing. Those comings and goings have promoted the exchange and integration of Chinese and Tibetan cultures, and help to spread and development of the Tibetan Buddhism in the history.

The main buildings in the Guangren Temple include, The Shadow Wall, The Imperial Stele Pavilion of Kangxi, The Drum Tower, The Bell Tower, The Guanyin Hall, The Logevity Hall, The Patronus Hall, The Temple of Wealth, The Thousand Buddhas Hall and the Sutra Collection Hall. Among them, the Sutra Collection Hall worshiped a 12-year-old statue of Gautama Buddha, which is one of the world's only 12-year-old statues of Gautama Buddha and has a high religious value. The other of which is in Jokang Temple, Lhasa. The hall of Protection faces east and west, and under the eaves of the main entrance hangs a plaque inscribed with "The sacred land of Budda", which was inscribed by Kang Youwei when he visited the Guangren Temple in Shaanxi in 1923. The main throne in the temple is dedicated to the Yamantaka, flanked by the Mahakala, yama Dharmaraja, Palden Lhamo and Sitabrahma.

\subsection{Extraction of the Element}

Each sect of the Tibetan Buddhism has both a common patronus and a patronus depending on the history of their different causs and effect by each sect. The Geru sect relies more on the King of Yama. [12] The Mahakala is located on the right side of the Yamantaka. Below, the symbolic elements of the statue are extracted and they were divided into three parts: pose, object and ornament.

First, the body part mainly pays attention to the characteristic of hair.

(1)Hairstyle. In the Tibetan Buddhist system to form as a wrath appearance, whether in the form of flat paintings, semi solid relief or three-dimensional round carvings, not only in the Mahakala or the Dharma are basically scattered and exaggerated in the form of rising anger, less variation in style.

(2)The eye on the forehead. The mahakala as a patronus statue or the six-armed was exceptionally valued by the Geru sect, both has the third eye on the forehead. It should be noticed that in the Tibetan Buddhism, the third eye on the forehead of patronus is roughly the same size as the other eyes on the face, but only slightly smaller.

(3) Ox-nose. The Mahakala on the Guangren Temple has a very huge and exaggerated oxen-shaped nose, which is not common in Mahakala statue. According to the research, there has not a concrete description on the Mahakala in other written record or the diagram record.

(4)Tusks. The function of patronus determines that the shape of its image must be angry, so the Mahakala statue opened big mouth, exposed tusks, and are in line with its identiy and basic "configuration".

Second. The object part mainly extracts this six-arm Mahakala's symbolic object

(1)Rosary beads. A piece of bone, a small skull rosary or skull shaped bone slide, usually in the form of 12, 16 and 21 beads held in the hand of the Mahakala in the Tibetan Buddhism. There are 21 beads were held in the arm of the Mahakala of Guangren Temple, and it symbolize 21 kinds of pure wisdom. 
(2)Trident. Also known as the pitchfork, in Tibetan Buddhism, the trident is not the only object of the Mahakala, but also the object of the goddess Pelden Lhamo, the concubine of the Mahakala. The trident in the Tibetan Buddhism symbolizes of breaking the "three poisons", turning primitive unknown into the fire of wisdom. In Tibetan, trident means "three point", has the similar meaning of "three toots" or "three families". The "three roots" refer to the trinity of "Buddha", "Dharma" and "Sangha" in Mahayana Buddhism, as well as the trinity of "Guru", "Mater", and "Dakini" in Vajrayana.[13] The Mahakala in the Guangren Temple hold a trident, craftsmanship is very sophisticated and simple. Except a oxtail whisk in the trident, there are no other repeated decoration.

(3)Battle-axe. In the book of "Tibetan Buddhism Symbol and the Pattern", the author explicitly states: "The canes, battle-axe, and the gabula bowl are the three major objects of the tantric female Yogini and Dakini. In fact, battle-axe and the gabula bowl were also common objects of the Mahakala. The Mahakala in the Guangren Temple has such object on the right lower nose.

(4) Skull bowl (Gabula bow). The Mahakala in Guangren Temple held the skeleton bowl in his two main arms. The skull bowl is made from the top half of the human skull, commonly kwon as the canopy of the heavens, and is also named as the gabula bowl. The patronus in the Tibetan Buddhism often holds the bowl to his chest with his left hand, like the statue in the Guangren Temple. The skeleton bowl has many forms of expression, and its contents include the brain, blood, wine, dew and so on.

Third, the ornaments only include the symbol of the visible part of the statue, while the unseen parts, such as the tiger skin and elephant skin will not be discussed.

(1) A ribbon or a snake? In the statue of the patronus, the snake often appears in the form of "snake lock", which means locking up the enemy or those who break the oath. In this Mahakala statue, from the waist on both sides to the ankle it was bent down and coiled up, with a certain momentum. Whether it is a snake or ribbon, we will be discussed it later part of the paper.

(2)Skulls and heads. The Mahakala statue has five skulls on its head. In the book of Deities of Tibetan Buddhism, 52 statues of the Mahakala were decorated with skulls, commonly names as dry strings, and human heads, which were named as wet strings. The skull is an important ornament of the patronus, but the waist of Mahakala statue of Guangren Temple is surrounded by silk cloth, so it could not see the exact ornaments. It can only be inferred from the religious texts, so this is a difficulty in the study of Tibetan Buddhism.

\subsection{The Relationship between India and the Hindu Statues}

First, I believe that inheritance is greater than rheology. Under the same frame of the statue, the Shiva terror phase and the six-arms Mahakala are given the "similar" intuitive feeling. Take the Ellora Caves No.29 cave, Dhumar Lena, the "Shiva kill the demons of darkness" as an example, his face shape was similar to this Mahakala, with the rage under the furrowed brows and eyes, has a third eyes, and shows the tusks and so on. The trident, the rosary and the skull bowl are all Shiva's objects, but in Shiva's different phases, they are also different. In addition, the terror phase of Shiva and its associated beggar phase appeared in the group sculpture forms as eight-arms or more than eight-arms, except those bronze statues with four-arms in the southern area of the Chola Dynasty. In the study of Shiva's terror phase, I tried to generalize the style of Shiva's terror phase and the summarized features are like this. "First, the head is shaped mainly by a hair crown with a crescent moon above and a prominent skull in the middle. Second, the facial expression is exaggerated and vicious, with the third eyes and prominent tusks. Third, most of them are undressed, due to the back-story of the ascetic state. Fourth, most of them are decorated with sacred lines made of skulls. Fifth, most of them have eight arms or more. Sixth, objects are slightly different according to different regions, but the basic elements include the trident, bowls made of skulls, ropes and so on." [1] Thus, except for the numbers of arms, hair and clothing, the six-armed Mahakala is similar to Shiva's terror phase. And in the description of the six-armed Mahakala, the tiger skin and the snake are usually seen in the clothing of Shiva. Review above, the snake-shaped ribbon on both sides of the Mahakala in Guangren Temple, I think it symbolizes both the ribbon and the snake. In Tibetan Buddhism, ribbons of different colors 
have different meanings and can be used for different rituals. For example, black is only used in the scariest rituals or the "evil gods" with wrath phase. This snake-shaped ribbon also exemplifies the shape of the statue in the exact origin but of different sects makes a compromise between inheritance and rheology.

Second, it shows that rheology and fusion are all in the details, and the symbolic connotation. First of all, the hair of the Mahakala became much more "simplified". Comparatively, Shiva's hairstyle has more changes and more accessories. The overall shape of hair can be divided into spread hair, hair with wearing bun and hair with bun crown. The accessories include the crescent moon, skull and small snakes. Secondly, the third eye on Shiva's terror phase is usually smaller than on the other two. In addition, although the mouth is open, only shows fangs. However, the statue of the Mahakala's three eyes is almost the same size, and the mouth was opened wildly exaggerated, and show the tusks and the curling tongue. These simplifications and exaggerations have relationship with the two religions and the task of the two gods. The simplification and exaggeration of the six-armed Mahakala statue point the Mahakala as the patronus. Spread and rising hair, exaggerated third eye, a backward curling tongue create its terrible image, played the role of "shock" and "guard". Finally, the treatment of the nose of the Mahakala in Guangren Temple, shows non-homologous fusion phenomenon in the iconographic rheology. While most of the Hindu statue of Shiva are based on human noses, the Mahakala of the Tibetan Buddhism's nose is like an animal's, such as ox's or pig's. Based on the study of literature and images, I think it is an ox nose. Because the temple is dedicated to the Yamantaka, who also named as the king of cow head, so the Mahakala and the Palden Lhamo are both represented as ox nose. It means both of the statues were influenced by the appearance of the form of the throne patonus. As Niu Le mentioned in his research, "when many religious beliefs collide and merge, the phenomenon of replacing with other image and similar function deities is very prominent." [14]

\section{Summary}

The statue of six armed Mahakala in the Dharma protection Hall of Guangren temple has a direct and visual connection with the Hindu God Shiva. These externalized factors are rooted in different and related religious cultures. In addition, within the same religious pedigree or between different religious pedigrees, the everyday use of the same element in the statues of gods, and the various interpretations of the same or similar symbols in inheritance and evolution are directly related to the functions of religions and the clergy of different gods. The similarities and differences between the Dharma protector God of Tibetan Buddhism and the three main gods of Hinduism, once again confirm the relationship of inheritance and development between Hinduism and Tibetan Buddhism, and the intuitive impact of the blending and collision of different religions is the change of god statue style.

\section{References}

[1] Le Zhang, Study on the statue of Shiva in India [D]. Xi' an Academy of Fine Arts, 2011, P.21-51.

[2] Longyu Yu, Reflections on Indian Culture[M]. Peking University Press,2008, P.114.

[3] Yao Wang, Into Tibetan Buddhism[M]. Zhong Hua Book Company,2013, P.30.

[4] Xue Hong, Tibetan Buddhism[M]. Sichuan Renmin Press,2015, P.22-82.

[5] Ling Li, Research on the image style of Mahakala[J]. Journal of Dunhuang Studies,2007(01):125-132.

[6] Keqiao Xue, Study on Mahakala [J]. South Asian Studies, 2013(03):146.

[7] Jiehua Huang, Han-Tibetan treasure Garland: Research on Dharma protector Mahakala belief[D]. Central University for Nationalities,2011, P.81-83.

[8] Rene De Nebesky-wojkowitz, Oracls \& Demons of Tibet. The Cult and Iconography of the Tibetan Protective Deities [M].Tibet people's Publishing House,1993, P.43. 
[9] Eckard Schleberger, The world of Indian gods-A Handbook of Hindu iconography[M]. ZhongXi Book Company, 2016, P.71.

[10] Yuemei Zhu, On the statues of Mahakala-Also on the relationship between the figures of Mahakala in Dali, Tibet and Dunhuang[J]. Dunhuang Research,2001(04):43-52.

[11] Boxin Li, Tibetan Buddhist temples in the city-A study of Guangren temple in Xi'an[D]. Northwest University for Nationalities, 2014, P.5.

[12] Jizeng Dang, Cross-regional spread, multi-ethnic communication and local variation-the "The Guardian of the treasure account" of Sakya Dharma protector from the perspective of historical texts, Tibet and Dunhuang[J]. Religious Studies,2021(03):194.

[13] Robert Beer, The hand book of Tibetan Buddhist symbols[M]. China Tibetology Publishing House,2007, P.137-197.

[14] Le Niu, Tracing the Rhinoceros\& Sea-the evolution and cultural representation of the folk belief in Mahakala in Hehuang and Taomin [J]. National Art,2019(04):43-52. 